\title{
Oxidation of Amino Acids by Chlorpromazine Cation Radical and Co-Catalysis by Chlorpromazine
}

\author{
Valdecir F. Ximenes, Giovana B. Quaggio, Fernanda S. Graciani, Manoel L. de Menezes
}

Department of Chemistry, Faculty of Science, Universidade Estadual Paulista, Bauru, Brazil

Email: vfximenes@fc.unesp.br

Received October $9^{\text {th }}, 2011$; revised November $4^{\text {th }}, 2011$; accepted December $10^{\text {th }}, 2011$

\begin{abstract}
The long-tem use of chlorpromazine (CPZ) may cause severe side effects. This property of CPZ might be related to pro-oxidant effects of the chlorpromazine cation radical $\left(\mathrm{CPZ}^{\circ+}\right)$, which can be easily generated by catalytic action of peroxidases, including the neutrophil myeloperoxidase (MPO) and by methemoglobin. Aiming the comprehension of a putative physiological effect of $\mathrm{CPZ}^{++}$upon biomolecules, in this work we studied the reactivity of $\mathrm{CPZ}^{++}$with amino acids and the co-catalytic effect of CPZ during the oxidation of amino acids by horseradish peroxidase $(\mathrm{HRP}) / \mathrm{H}_{2} \mathrm{O}_{2}$ system. We also studied whether natural blood plasma components as ascorbic acid, uric acid and nitrite could inhibit the oxidative effect of $\mathrm{CPZ}^{+}$. We found that tryptophan, tyrosine and cysteine were easily oxidized by pure $\mathrm{CPZ}^{\circ+}$. Other amino acids as methionine, glycine, phenylalanine, aspartic acid and lysine were unreactive. The decomposition of $\mathrm{CPZ}^{++}$was exacerbated by uric acid, ascorbic acid and nitrite, provoking inhibition in the amino acids oxidation. In experiments with $\mathrm{HRP} / \mathrm{H}_{2} \mathrm{O}_{2}$, and using $\mathrm{CPZ}$ as a co-catalyst, a strong effect upon oxidation of tryptophan, tyrosine and cysteine was obtained. It was also found that tryptophan was more reactive than tyrosine with $\mathrm{CPZ}^{\circ+}$, a feature that could be related to the recently described favorable interaction between tryptophan and CPZ. The use of CPZ as a co-catalyst is discussed regarding its role in the efficient oxidation of tryptophan.
\end{abstract}

Keywords: Tryptophan; Tyrosine; Nitrite; Chlorpromazine; Horseradish Peroxidase

\section{Introduction}

Chlorpromazine (CPZ) is a neuroleptic drug of the phenothiazine family and is widely used in the treatment of schizophrenia [1]. However, the long-term use may cause severe side effects [2], which in many cases have been related to oxidative damage. Regarding hepatotoxicity, which is one of the major concerns during the clinical use of CPZ, this neuroleptic drug is able to inhibit intracellular carboxylesterases, such as alpha-naphthyl acetate esterase, naphthol chloroacetate esterase, and alphanaphthyl butyrate esterase in hepatocytes [3]. Melatonin, a largely used antioxidant, when administered with CPZ, significantly attenuated the oxidative stress parameters as evidenced by lowering malondialdehyde levels in tissue homogenate [4]. In the brain, the level of the lipid peroxidation product, hydroxyalkanals, is increased when the rats are treated of CPZ [5].

The above chemical features of $\mathrm{CPZ}$ might be related to the pro-oxidant effect of chlorpromazine cation radical $\left(\mathrm{CPZ}^{\circ+}\right)$, which can be easily generated by catalytic action of peroxidases, including the neutrophil myeloper- oxidase (MPO) and by methemoglobin [6,7]. For instance, the in vitro involvement of $\mathrm{CPZ}^{\circ+}$ during the oxidation of biomolecules has been well-established for catecholamines, ascorbate, GSH, NADH and melatonin [8-10]. Additionally, enzymes are inactivated by $\mathrm{CPZ}^{+}$. This is the case for cholinesterase in rat serum [11], and for trypanosoma cruzi dihydrolipoamide dehydrogenase, through its interaction with phenothiazine radicals generated by MPO or horseradish peroxidase (HRP)/ $\mathrm{H}_{2} \mathrm{O}_{2}$ systems [12].

For the reasons stated above, here we aimed to study the reactivity of $\mathrm{CPZ}^{+}$with amino acids. The experimental approaches were the direct reaction between $\mathrm{CPZ}^{++}$ and amino acids and the co-catalysis effect of CPZ when the amino acids were submitted to oxidation by HRP/ $\mathrm{H}_{2} \mathrm{O}_{2}$.

\section{Materials and Methods}

\subsection{Chemicals}

Tryptophan, tyrosine, cysteine, methionine, glycine, 
phenylalanine, aspartic acid, lysine, uric acid, $\mathrm{NaNO}_{2}$, ascorbic acid, 5,5'-dithiobis(2-nitrobenzoic) acid (DTNB), horseradish peroxidase (HRP) (EC 1.11.1.7) and chlorpromazine were purchased from Sigma-Aldrich Chemical Co. (St. Louis, MO, USA). Hydrogen peroxide $\left(\mathrm{H}_{2} \mathrm{O}_{2}\right)$ was prepared by diluting a $30 \%$ stock solution and calculating its concentration $\left(\varepsilon_{240 \mathrm{~nm}}=43.6 \mathrm{M}^{-1} \cdot \mathrm{cm}^{-1}\right)$. All the reagents used for buffers and mobile phase were of analytical grade.

\subsection{Oxidation of Amino Acids by Pre-Formed $\mathrm{CPZ}^{++}$}

Solutions of $\mathrm{CPZ}^{++}$were prepared as follows: CPZ (1 $\mathrm{mM}$ ) was dissolved in $\mathrm{pH} 3.8$ glycine buffer $(20 \mathrm{mM})$. Then, $0.1 \mu \mathrm{M}$ HRP and $100 \mu \mathrm{M} \mathrm{H}_{2} \mathrm{O}_{2}$ were added and the reaction was allowed to proceed to completion (1 min). The initial concentration of $\mathrm{CPZ}^{\circ+}$ was calculated using its extinction coefficient $\varepsilon_{525 \mathrm{~nm}}=12.100 \mathrm{M}^{-1} \cdot \mathrm{cm}^{-1}$ [13]. Considering the absorbance obtained of 1.4, the initial concentration of $\mathrm{CPZ}^{*+}$ was $115 \mu \mathrm{M}$. The amino acids were added $20 \mathrm{~s}$ after the formation of $\mathrm{CPZ}^{++}$. The experiments were monitored using a Hewlett Packard 8452 diode array spectrophotometer.

For the HPLC studies, the reaction mixtures were incubated for $10 \mathrm{~min}$ at $25^{\circ} \mathrm{C}$ and injected into the HPLC system. Determinations of tryptophan and tyrosine consumptions were carry out using HPLC combined with diode array detection. The separation was performed on a $15 \times 6.0 \mathrm{~mm}$ i.d., $5 \mu \mathrm{m}, 100 \AA$, C18 Shin-pack column (Shimadzu, Kyoto, Japan). The HPLC system (Jasco, Tokyo, Japan) consisted of a PU-2089s quaternary gradient pump, a CO-2060 column oven set at $25^{\circ} \mathrm{C}$ and a MD-2015 diode array detector. The reaction mixtures were separated were separated by using a gradient of water (solvent $\mathrm{A}$ ) and methanol (solvent B), programmed as follows: $0-10 \mathrm{~min}$ from 95 to $70 \% \mathrm{~A}, 10-15 \mathrm{~min}$ from $70 \%-95 \%$ A. The total flow rate of the mobile phase was $1.0 \mathrm{~mL} / \mathrm{min}$ and the injection volume was 20 $\mu \mathrm{L}$. The diode array detector wavelength of $260 \mathrm{~nm}$ was used to monitor tryptophan consumption and 230 to monitor tyrosine consumption.

\subsection{Oxidation of Tryptophan and Tyrosine: Co-Catalysis by CPZ}

In these experiments $\mathrm{CPZ}^{+}$was not pre-formed as above. The reaction mixtures were constituted by tryptophan 50 $\mu \mathrm{M}$ or tyrosine $50 \mu \mathrm{M}$, HRP $0.1 \mu \mathrm{M}, \mathrm{CPZ} 10 \mu \mathrm{M}, \mathrm{H}_{2} \mathrm{O}_{2}$ $100 \mu \mathrm{M}$ in $10 \mathrm{mM} \mathrm{PBS} \mathrm{pH} 7.4$ at $25^{\circ} \mathrm{C}$ in the presence or absence of the alternative substrates. The reactions were triggered by adding $\mathrm{H}_{2} \mathrm{O}_{2}$ and incubated by $10 \mathrm{~min}$. After oxidation, the remaining concentration of tryptophan and tyrosine were analyzed by HPLC as above.

\subsection{Oxidation of Tryptophan: Comparison between Co-Catalysis by CPZ and Oxidation Using High Concentration of $\mathrm{H}_{2} \mathrm{O}_{2}$. Consumption of Tryptophan and Formation of Products}

Using CZP as a co-catalyst the reaction mixtures were constituted by $1 \mathrm{mM}$ tryptophan, $2 \mathrm{mM} \mathrm{H} \mathrm{H}_{2} \mathrm{O}_{2}, 100 \mu \mathrm{M}$ $\mathrm{CPZ}$ and $1 \mu \mathrm{M}$ HRP in PBS pH 7.4 at $25^{\circ} \mathrm{C}$ and incubated for $10 \mathrm{~min}$. Using high concentration of $\mathrm{H}_{2} \mathrm{O}_{2}$, the oxidation was performed as previously described, as follows: reaction mixtures were $1 \mathrm{mM}$ tryptophan dissolved in $0.1 \mathrm{M}$ borate buffer $\mathrm{pH} 6.3 . \mathrm{H}_{2} \mathrm{O}_{2}$ was added hourly (final concentration of $1.0 \mathrm{M}$ ) for $6 \mathrm{~h}$ at $37^{\circ} \mathrm{C}$ in dark as previously reported [14]. In both methods the separation of oxidation products was carry out isocratically on a 15 $\times 6.0 \mathrm{~mm}$ i.d., $5 \mu \mathrm{m}, 100 \AA$, C18 Shin-pack column, using a mixture of solvents composed of $0.1 \%$ acetic acid (94\%) and methanol (6\%). The total flow rate of the mobile phase was $1.0 \mathrm{ml} / \mathrm{min}$ and the injection volume was $20 \mu \mathrm{l}$.

\subsection{Oxidation of Cysteine and Co-Catalysis by CPZ}

Cysteine $(1 \mathrm{mM})$ was incubated with $0.1 \mu \mathrm{M}$ HRP, 100 $\mu \mathrm{M} \mathrm{H}_{2} \mathrm{O}_{2}$ in $10 \mathrm{mM}$ PBS $\mathrm{pH} 7.4$ at $25^{\circ} \mathrm{C}$ in the presence or absence $25 \mu \mathrm{M} \mathrm{CPZ}$. The reactions were triggered by adding $\mathrm{H}_{2} \mathrm{O}_{2}$ and stopped at regular intervals by adding $20 \mu \mathrm{g} / \mathrm{ml}$ catalase. The remaining concentration of cysteine was analyzed by the reduction of DTNB as follows: $450 \mu \mathrm{l}$ of the reaction mixture was added to $450 \mu \mathrm{l}$ of 300 $\mathrm{mM} \mathrm{Na} \mathrm{HPO}_{4}$ and $100 \mu \mathrm{l}$ of DTNB solution $(20 \mathrm{mg}$ DTNB in $100 \mathrm{ml} 1.0 \%$ sodium citrate). The absorbance was read at $412 \mathrm{~nm}$ using PBS as blank [15]. A standard curve was generated for calculation of cysteine concentration.

\section{Results}

The stability of $\mathrm{CPZ}^{\circ+}$ is strongly dependent of the identity, concentration and $\mathrm{pH}$ of the buffer. Here, we used $20 \mathrm{mM}$ pH 3.8 glycine buffer, where $\mathrm{CPZ}^{++}$attained its higher lifetime [16]. $\mathrm{CPZ}^{++}$was prepared through oxidation of CPZ catalyzed by HRP, where the cation radical was stable for at least $20 \mathrm{~min}$. The concentration of $\mathrm{CPZ}^{+}$, calculated based in its excitation coefficient at $525 \mathrm{~nm}$, was about $100 \mu \mathrm{M}$ [13].

To study the reactivity between the amino acids and $\mathrm{CPZ}^{++}$, these compounds were added in the pre-formed $\mathrm{CPZ}^{++}$. Figure 1 shows that only tryptophan, tyrosine and cysteine, provoked a fast decay in the concentration of $\mathrm{CPZ}^{++}$. Lysine, aspartic acid, methionine and phenylalanine were unreactive. The kinetic experiment also revealed a higher reactivity between $\mathrm{CPZ}^{++}$and tryptophan 


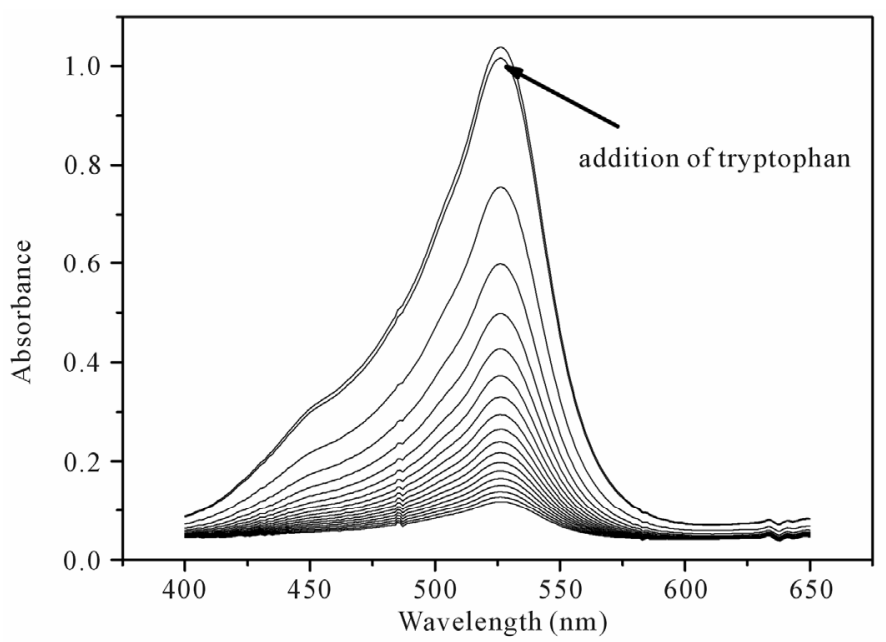

(a)

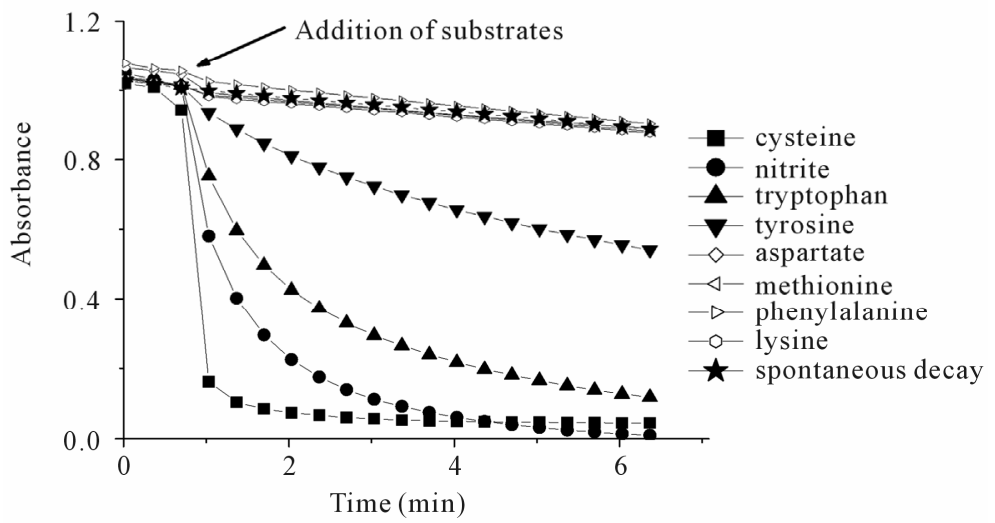

(b)

Figure 1. Effect of amino acids and nitrite on $\mathrm{CPZ}^{++}$. $\mathrm{CPZ}^{++}$was pre-formed as described in materials and methods. (a) $\mathrm{UV}$-Vis absorption band of $\mathrm{CPZ}^{++}$and its bleaching by tryptophan. The scans were taken every $20 \mathrm{~s}$. (b) Decay of $\mathrm{CPZ}^{\circ+}$ provoked by amino acids or nitrite $(50 \mu \mathrm{M})$. The substrates were added $40 \mathrm{~s}$ after the formation of $\mathrm{CPZ}^{\circ+}$.

when compared to tyrosine.

The spontaneous bleaching of $\mathrm{CPZ}^{+}$is caused by its reaction with the buffer components, including water and other nucleophiles, which lead to the parent $\mathrm{CPZ}$ and CPZ-sulfoxide [16]. Here, searching for biomolecules that could react with $\mathrm{CPZ}^{\circ+}$, we found that nitrite anion $\left(\mathrm{NO}_{2}^{-}\right)$, which is present in high concentration in the blood plasma, increased significantly the decay of $\mathrm{CPZ}^{++}$ (Figure 1). However, $\mathrm{NO}_{2}^{-}$was not consumed during the reaction. The analysis of $\mathrm{NO}_{2}^{-}$was performed by measuring its concentration before and after the bleaching of $\mathrm{CPZ}^{\circ+}$ (Griess method, not shown).

Considering that some compounds provoke the bleaching of $\mathrm{CPZ}^{++}$but are not oxidized, the concentration of amino acids were measured after the reactions. The results in Tables 1-2 show that $\mathrm{CPZ}^{\circ+}$ was able to oxidize these amino acids. The results also show that others substrates, which are normally present in the blood plasma, were able to compete and partially inhibit the oxidation of tyrosine and tryptophan. Additionally, the results in
Tables 1-2 show the higher reactivity of $\mathrm{CPZ}^{+}$with tryptophan when compared to tyrosine and confirm the kinetic experiments. How depicted in the tables, tryptophan inhibited the oxidation of tyrosine in $59 \%$, while tyrosine inhibited the oxidation of tryptophan in only $18 \%$.

Besides the oxidizing capacity of $\mathrm{CPZ}^{++}$, it was also found that $\mathrm{CPZ}$ is able to act as a co-catalyst during the HRP-catalyzed oxidation of amino acids by $\mathrm{H}_{2} \mathrm{O}_{2}$. In these experiments, $\mathrm{CPZ}^{++}$was not pre-formed, but generated during the reaction. The data in Table 3 show that tryptophan was completely unreactive under this experimental condition, but was almost completed oxidized in the presence of CPZ, which was used in a concentration 5 times lower than tryptophan. Similar results were obtained to tyrosine (Table 4). The inhibitory effect of alternatives substrates upon oxidation of tryptophan and tyrosine was also studied using $\mathrm{CPZ}$ as a co-catalyst. In this case the inhibitory effect was significantly lower compared to the experiments with pre-formed $\mathrm{CPZ}^{++}$. 
Table 1. Oxidation of tryptophan by pre-formed $\mathrm{CPZ}^{\circ+}$ and effect of alternative substrates.

\begin{tabular}{ccc}
\hline Reaction System & $\begin{array}{c}\text { Oxidized Tryptophan } \\
(\boldsymbol{\mu M})\end{array}$ & $\begin{array}{c}\text { Inhibitory Effect on } \\
\text { Tryptophan Oxidation (\%) }\end{array}$ \\
\hline Control & $41.9 \pm 1.0$ & - \\
+ nitrite & $13.2 \pm 2.0$ & 68.5 \\
+ cysteine & $10.3 \pm 0.5$ & 75.4 \\
+ ascorbic acid & $23.0 \pm 0.7$ & 45.1 \\
+ uric acid & $11.8 \pm 0.8$ & 71.8 \\
+ tyrosine & $34.3 \pm 4.0$ & 18.1 \\
\hline
\end{tabular}

Control: $\mathrm{CPZ}^{+} 110 \mu \mathrm{M}$, tryptophan $50 \mu \mathrm{M}$ in $20 \mathrm{mM}$ glycine buffer, $\mathrm{pH} 3.8$ at $25^{\circ} \mathrm{C}$. The alternative substrates $(50 \mu \mathrm{M})$ were previously mixed with tryptophan and the mixture added after formation of $\mathrm{CPZ}^{+}$. The remaining concentration of tryptophan was analyzed by HPLC.

Table 2. Oxidation of tyrosine by pre-formed $\mathrm{CPZ}^{\circ+}$ and effect of alternative substrates.

\begin{tabular}{ccc}
\hline Reaction System & $\begin{array}{c}\text { Oxidized Tyrosine } \\
(\boldsymbol{\mu M})\end{array}$ & $\begin{array}{c}\text { Inhibitory Effect on } \\
\text { Tyrosine Oxidation (\%) }\end{array}$ \\
\hline control & $47.6 \pm 1.7$ & - \\
+ nitrite & $2.0 \pm 1.0$ & 95.8 \\
+ cysteine & $4.8 \pm 1.2$ & 8.9 \\
+ ascorbic acid & $24.4 \pm 3.1$ & 48.7 \\
+ uric acid & $7.4 \pm 2.8$ & 84.6 \\
+ tryptophan & $19.4 \pm 5.9$ & 59.2 \\
\hline
\end{tabular}

Control: $\mathrm{CPZ}^{++} 110 \mu \mathrm{M}$, tyrosine $50 \mu \mathrm{M}$ in $20 \mathrm{mM}$ glycine buffer, $\mathrm{pH} 3.8$ at $25^{\circ} \mathrm{C}$. The alternative substrates $(50 \mu \mathrm{M})$ were previously mixed with tyrosine and the mixture added after formation of $\mathrm{CPZ}^{+}$. The remaining concentration of tyrosine was analyzed by HPLC. The results are mean and SD of triplicates.

Table 3. Oxidation of tryptophan by $\mathrm{HRP} / \mathrm{H}_{2} \mathrm{O}_{2}$ and cocatalysis of CPZ: effect of alternative substrates.

\begin{tabular}{ccc}
\hline Reaction System & $\begin{array}{c}\text { Oxidized Tryptophan } \\
(\boldsymbol{\mu M})\end{array}$ & $\begin{array}{c}\text { Inhibitory Effect on } \\
\text { Tryptophan Oxidation (\%) }\end{array}$ \\
\hline without CPZ & 0 & - \\
control & $26.4 \pm 2.0$ & - \\
+ nitrite & $22.5 \pm 3.9$ & 14.8 \\
+ cysteine & $19.0 \pm 4.7$ & 28.0 \\
+ ascorbic acid & $17.2 \pm 5.6$ & 34.8 \\
+ uric acid & $9.8 \pm 2.8$ & 62.9 \\
+ tyrosine & $7.2 \pm 1.7$ & 72.7 \\
\hline
\end{tabular}

Control: Tryptophan $50 \mu \mathrm{M}$, HRP $0.1 \mu \mathrm{M}, \mathrm{CPZ} 10 \mu \mathrm{M}, \mathrm{H}_{2} \mathrm{O}_{2} 100 \mu \mathrm{M}$ in 10 $\mathrm{mM}$ PBS, $\mathrm{pH} 7.4$ at $25^{\circ} \mathrm{C}$. The reactions were triggered by adding $\mathrm{H}_{2} \mathrm{O}_{2}$ and incubated by $10 \mathrm{~min}$. When present, the alternative substrates $(50 \mu \mathrm{M})$ were added before $\mathrm{H}_{2} \mathrm{O}_{2}$. The remaining concentration of tryptophan was analyzed by HPLC. The results are mean and SD of triplicates.
Table 4. Oxidation of tyrosine by $\mathrm{HRP} / \mathrm{H}_{2} \mathrm{O}_{2}$ and co-catalysis of CPZ: effect of alternative substrates.

\begin{tabular}{ccc}
\hline Reaction System & $\begin{array}{c}\text { Oxidized Tyrosine } \\
(\boldsymbol{\mu M})\end{array}$ & $\begin{array}{c}\text { Inhibitory Effect on } \\
\text { Tyrosine Oxidation }(\%)\end{array}$ \\
\hline without CPZ & $6.2 \pm 0.8$ & - \\
control & $41.6 \pm 0.6$ & - \\
+ nitrite & $39.9 \pm 0.8$ & 4.1 \\
+ cysteine & $38.3 \pm 0.8$ & 7.9 \\
+ ascorbic acid & $38.2 \pm 0.7$ & 8.1 \\
+ uric acid & $16.4 \pm 0.7$ & 60.6 \\
+ Tryptophan & $35.5 \pm 0.3$ & 14.4 \\
\hline
\end{tabular}

Control: Tyrosine $50 \mu \mathrm{M}$, HRP $0.1 \mu \mathrm{M}, \mathrm{CPZ} 10 \mu \mathrm{M}, \mathrm{H}_{2} \mathrm{O}_{2} 100 \mu \mathrm{M}$ in 10 mM PBS, pH 7.4 at $25^{\circ} \mathrm{C}$. The reactions were triggered by adding $\mathrm{H}_{2} \mathrm{O}_{2}$ and incubated by $10 \mathrm{~min}$. When present, the alternative substrates $(50 \mu \mathrm{M})$ were added before $\mathrm{H}_{2} \mathrm{O}_{2}$. The remaining concentration of tryptophan was analyzed by HPLC. The results are mean and SD of triplicates.

The co-catalytic effect of CPZ was studied by UV-Vis measurements and demonstrated the concentration dependent effect of CPZ on HRP-catalyzed oxidation of tryptophan. Similar results were observed by monitoring the decay of native tryptophan fluorescence (Figure 2).

The efficiency of tryptophan oxidation using $\mathrm{CPZ}$ as a co-catalyst was compared with a recently reported method, which is based in the use of high concentration of $\mathrm{H}_{2} \mathrm{O}_{2}(1 \mathrm{M})$ in borate $\mathrm{pH} 6.3$ buffer [14]. Using the method developed here and $1 \mathrm{mM}$ of tryptophan, the consumption of tryptophan was $0.71 \pm 0.05 \mathrm{mM}$ and the reaction was completed in $15 \mathrm{~min}$. By using the reported method, after an incubating for $6 \mathrm{~h}$, the consumption was $0.12 \pm 0.05 \mathrm{mM}$. These are mean and SD of three experiments. Figure 3 shows the chromatograms of the reaction mixtures using both methods. The products (peaks) were also similar in both methods.

CPZ was also an effective co-catalyst to cysteine. In this case, after the incubation with HRP and $\mathrm{H}_{2} \mathrm{O}_{2}$, the remaining concentration of cysteine was measured by the reduction of DTNB (Figure 4).

\section{Discussion}

The inhibitory effect of $\mathrm{CPZ}^{\circ+}$ upon enzyme activity $[11,12]$ is probably related to protein oxidative damage. Here, our results reinforce this proposal since $\mathrm{CPZ}^{\circ+}$ oxidized easily the amino acids tryptophan, tyrosine and cysteine. As well established in the scientific literature, the oxidation of these amino acids has been implicated in the loss of functions of protein and has been detected in physiologically important proteins [17-19]. Here, special attention was given to tryptophan, since this amino acid was more reactive than tyrosine with $\mathrm{CPZ}^{\circ+}$. The higher reactivity between $\mathrm{CPZ}^{++}$and tryptophan could be related 


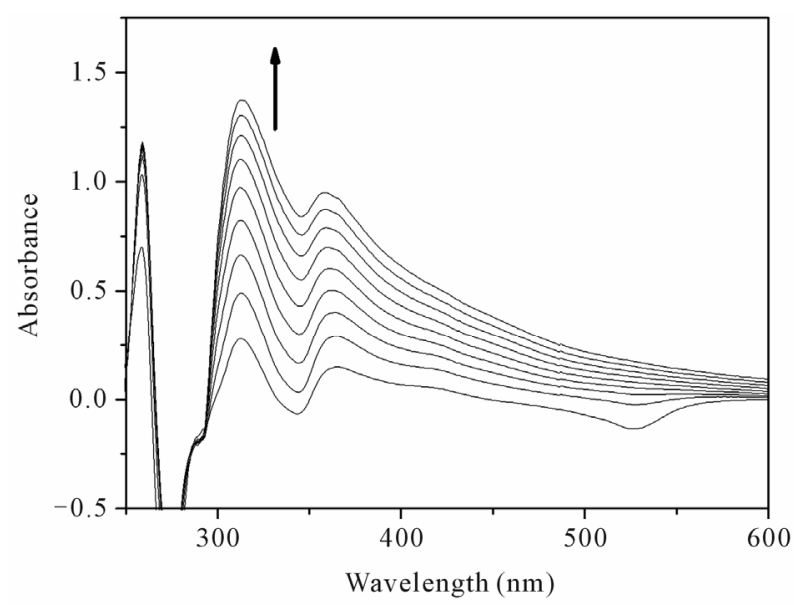

(a)

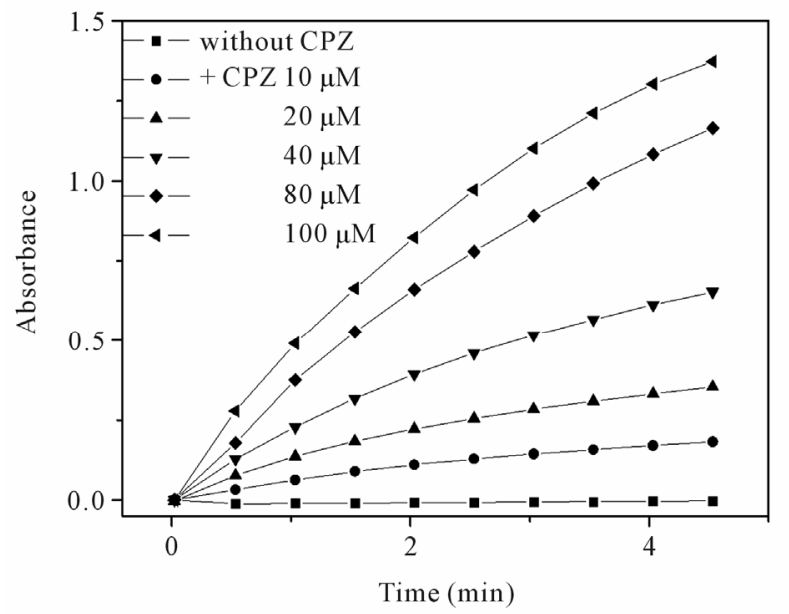

(b)

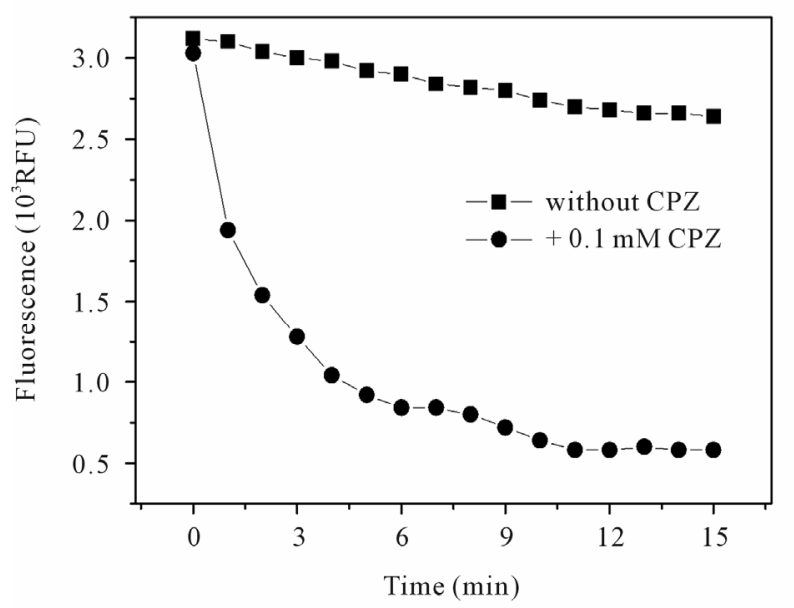

(c)

Figure 2. Oxidation of tryptophan: Co-catalysis by CPZ. (a) UV-Vis difference spectra obtained during oxidation of tryptophan. The scans were taken at $30 \mathrm{~s}$ intervals. (b) Concentration-dependent effect of CPZ on tryptophan oxidation. (c) The oxidation of tryptophan monitored by its native fluorescence $\left(\varepsilon_{\mathrm{ex}}=290, \varepsilon_{\mathrm{em}}=\mathbf{3 6 0}\right)$. The reaction mix-

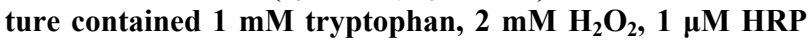
in PBS pH 7.4 at $25^{\circ} \mathrm{C}$.
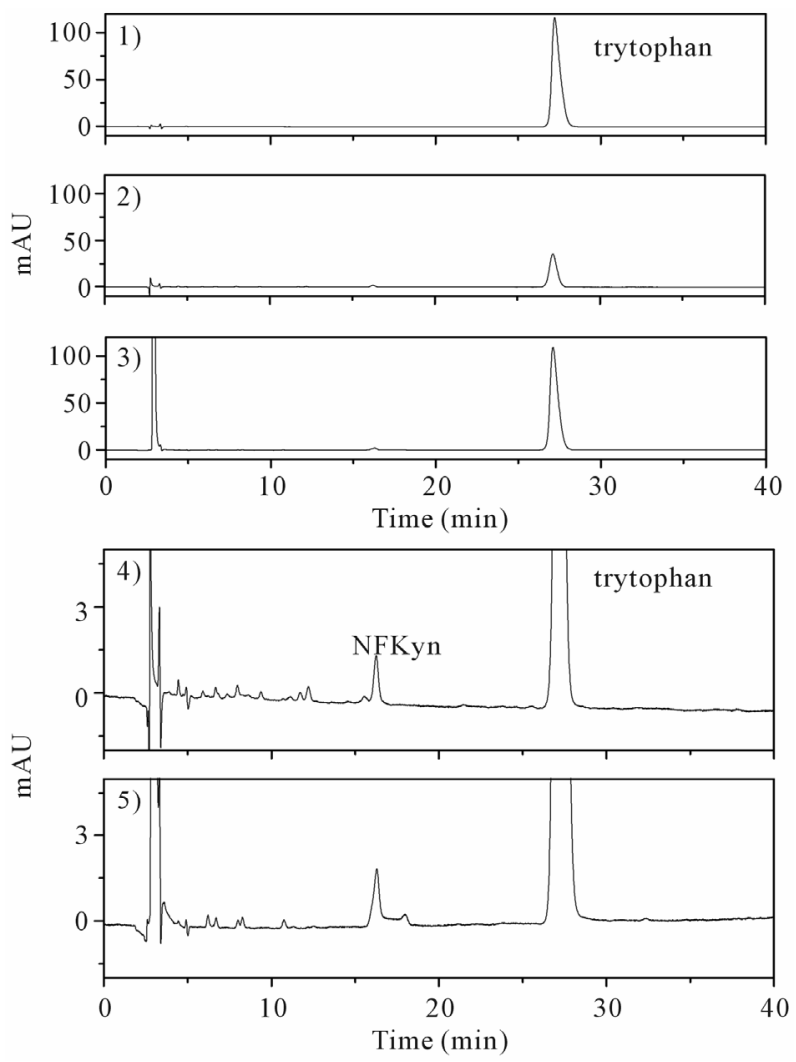

Figure 3. Efficiency of oxidation of the tryptophan: comparison between co-catalysis by $\mathrm{CPZ}$ and oxidation by high concentration of $\mathrm{H}_{2} \mathrm{O}_{2}$. 1) Standard of tryptophan $1 \mathrm{mM}$; 2) Remaining tryptophan, 10 minutes after the beginning of the reaction using $\mathrm{CPZ}$. The reaction mixture contained 1

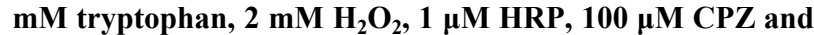
in PBS pH 7.4 at $25^{\circ} \mathrm{C}$; 3) Remaining tryptophan, 6 hour after the beginning of the reaction using $1 \mathrm{M} \mathrm{H}_{2} \mathrm{O}_{2}$. The reaction mixture contained $1 \mathrm{mM}$ tryptophan and $1 \mathrm{M}$ $\mathrm{H}_{2} \mathrm{O}_{2}$; 4) Products using $\mathrm{CPZ}$ (expanded chromatogram 2). 5) Products using $1 \mathrm{M} \mathrm{H}_{2} \mathrm{O}_{2}$ (expanded chromatogram 3). $\mathrm{N}$-formylkynurenine (NFkyn).

to favorable interaction between this amino acid and CPZ as have been verified by suppression of fluorescence of serum albumin by CPZ [20]. In the same direction, the inactivation of cholinesterase induced by $\mathrm{CPZ}^{++}$was correlated with depletion of tryptophan residues [13].

Considering the formation of $\mathrm{CPZ}^{\circ+}$ and its putative deleterious consequences in the physiological medium, it should be also consider the presence of other oxidizable metabolites that could interact and neutralize this oxidant. For this reason, we compared the relative efficacy of oxidation of tryptophan and tyrosine when compound as nitrite, ascorbate, cysteine and uric acid, which are natural components from blood plasma, were added in the reaction mixture. The significant inhibition in the oxidation of tryptophan and tyrosine obtained when these alternative metabolites were added in the reaction mixture is an indication that $\mathrm{CPZ}^{\cdot+}$ can be reduced by many other 


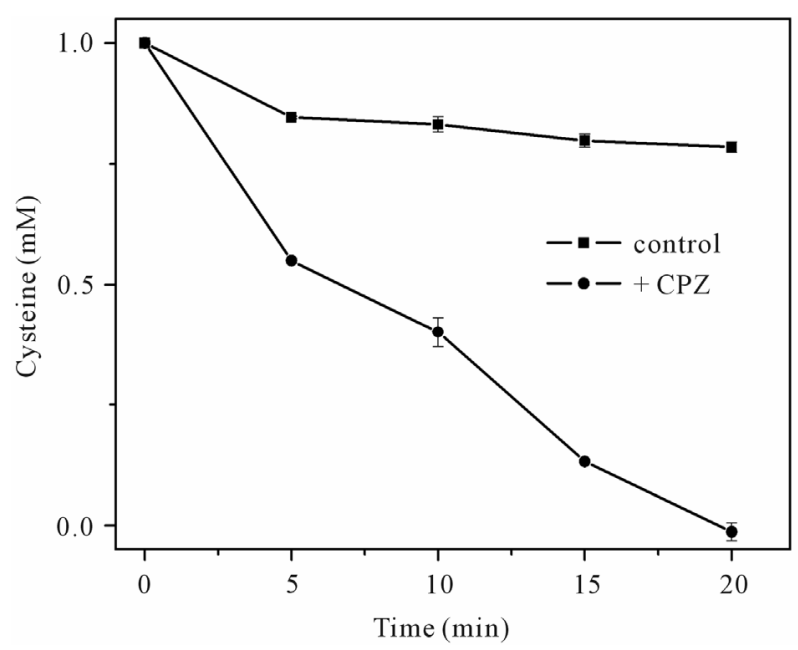

Figure 4. Oxidation of cysteine: Co-catalysis by CPZ. The reaction mixture (control) contained $1 \mathrm{mM}$ cysteine, 100 $\mu \mathrm{M} \mathrm{H}_{2} \mathrm{O}_{2}, 0.1 \mu \mathrm{M}$ HRP in PBS pH 7.4 at $25^{\circ} \mathrm{C}$. When present $25 \mu \mathrm{M}$ CPZ. The remaining concentration of cysteine was measured with DTNB. The results are mean and SD of triplicates.

oxidizable and non-oxidizable endogenous compounds. The last case is applicable to nitrite, since this metabolite is not oxidized by $\mathrm{CPZ}^{+}$, but increased its rate of spontaneous decomposition and, as a consequence, inhibited the oxidation of tyrosine and tryptophan. However, the efficacy of the alternative endogenous substrates used here as inhibitor of tryptophan and tyrosine oxidations was significantly lower when $\mathrm{CPZ}$ acted as a co-catalyst. For instance, the effect of nitrite could be considered, as it caused strong effect on $\mathrm{CPZ}^{++}$stability. In the experiments with pre-formed $\mathrm{CPZ}^{\text {+ }}$ the inhibition of oxidation was $73 \%$ and $100 \%$ for tryptophan and tyrosine, respectively. In the experiments using $\mathrm{CPZ}$ as a co-catalyst, the inhibitions were only $14 \%$ and $4 \%$, respectively. The main difference between these experiments is that using $\mathrm{CPZ}$ as a co-catalyst, $\mathrm{CPZ}^{+}$acts as a transient intermediate, that is not accumulated during the reaction course. A mechanism proposal, for the lower inhibitory effect of nitrite in this case, would be an interaction between $\mathrm{CPZ}^{*+}$ and tryptophan or tyrosine close the active site of HRP. In other words, $\mathrm{CPZ}^{++}$would not diffuse into the bulk solution. Finally, since the action of $\mathrm{CPZ}$ as a co-catalyst is a condition closer that could be found in the physiological medium, we propose, that the oxidation of amino acids can really take place and be involved in proteins damage when patients are chronically submitted to treatment with this neuroleptic drug. The scheme depicted in Figure 5 presents a proposal for the involvement of $\mathrm{CPZ}$ during the oxidation of amino acids.

Considering yet the effect of $\mathrm{CPZ}$ as a co-catalyst during tryptophan oxidation, it must be considered that this amino acid is particularly unreactive with $\mathrm{HRP} / \mathrm{H}_{2} \mathrm{O}_{2}$.

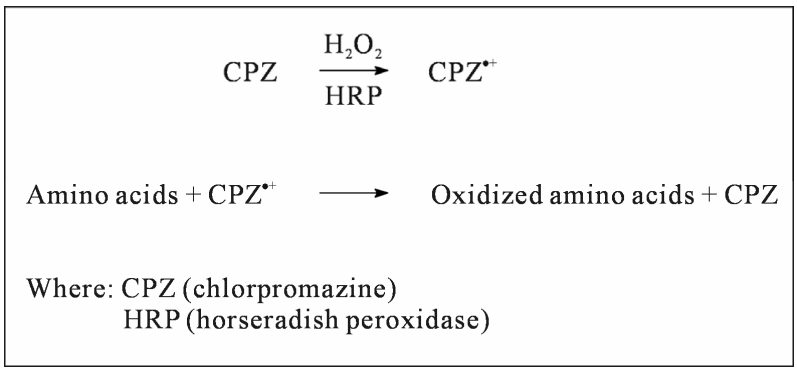

Figure 5. Proposal for the involvement of $\mathrm{CPZ}$ as a cocatalyst during the oxidation of amino acids.

Indeed, the oxidation of indole derivatives by $\mathrm{H}_{2} \mathrm{O}_{2}$, and catalyzed by peroxidases as HRP or MPO, is dependent of the reduction potentials of these compounds. For tryptophan $\left(\mathrm{E}^{\circ}=1.015 \mathrm{~V}\right)$, the bimolecular rate constant for its reaction with the active form compound-II (HRP-II) is $6.9 \pm 1.3$. For melatonin $\left(\mathrm{E}^{\circ}=0.95 \mathrm{~V}\right)$, the rate constant increase to $(9.6 \pm 0.3) \times 10^{2}$. For additional comparison, tyrosine a phenolic compound $\left(\mathrm{E}^{\circ}=0.93\right)$, the rate constant reached $(1.6 \pm 0.6) \times 10^{4}[21]$. Here, this poor reactivity of tryptophan was confirmed when $1 \mathrm{mM}$ was submitted to oxidation with $2 \mathrm{mM} \mathrm{H}_{2} \mathrm{O}_{2}$ and $1 \mu \mathrm{M}$ HRP. In this case, our results demonstrated that no more than $18 \mu \mathrm{M}$ was oxidized in such condition. However, in the presence of $\mathrm{CPZ}$ as a co-catalyst the uptake reached $710 \mu \mathrm{M}$.

The comparison between the efficiency of tryptophan oxidation using our method (tryptophan $1 \mathrm{mM}, \mathrm{H}_{2} \mathrm{O}_{2} 1$ $\mathrm{mM}$, HRP $1 \mu \mathrm{M}$ and $0.1 \mathrm{mM} \mathrm{CPZ}$ ), where $710 \mu \mathrm{M}$ of tryptophan was consumed in $10 \mathrm{~min}$, with the described method, that use high concentration of $\mathrm{H}_{2} \mathrm{O}_{2}(1 \mathrm{mM}$ tryptophan and $1 \mathrm{M} \mathrm{H}_{2} \mathrm{O}_{2}$ ), where the consumption was $120 \mu \mathrm{M}$ after $6 \mathrm{~h}$ [14], demonstrated the efficacy of CPZ as a co-catalyst. It was not our interest the identification of tryptophan's oxidation products, however, a comparison of the chromatogram peaks profile, with the reported method above, shows that similar products were obtained using CPZ. Among these, it was found a peak that has retention time and UV-Vis spectrum (not shown) that matched the product of oxidative cleavage of the indole ring, $N$-formylkynurenine.

Besides tryptophan and tyrosine, and how could be expected for a sulfhydryl compound, cysteine was also easily oxidized by $\mathrm{CPZ}^{++}$and by $\mathrm{CPZ}$ as a co-catalyst. This is clear evidence and suggests that proteins could be cross-linked by interacting with this neuroleptic drug.

In conclusion, the high reactivity of oxidizable amino acids with $\mathrm{CPZ}$ confirms the potential deleterious effect of this drug regarding protein damages. The particular efficacy of tryptophan oxidation using $\mathrm{CPZ}$, when compared to oxidation mediated by peroxidase alone, could be a useful method to produce oxidized tryptophan residues in protein. Indeed, there is a current interest in the 
development of analytical procedure that could detect oxidized tryptophan in proteins $[22,23]$. Hence, using the method developed here, the production of protein with oxidized tryptophan could easily achieve.

\section{Acknowledgements}

This work was supported by grants from Fundação de Amparo à Pesquisa do Estado de São Paulo (Fapesp) and from Conselho Nacional de Desenvolvimento Científico e Tecnológico (CNPq).

\section{REFERENCES}

[1] S. De Haan and X. Liu, "Chlorpromazine Dose for People with Schizophrenia," Schizophrenia Bulletin, Vol. 35, No. 3, 2009, pp. 491-492. doi: 10.1093/schbul/sbp014

[2] J. W. Newcomer, "Antipsychotic Medications: Metabolic and Cardiovascular Risk," The Journal of Clinical Psychiatry, Vol. 68, No. 4, 2007, pp. 8-13.

[3] L. Radenovic and G. Kartelija, "Effect of Chlorpromazine on Human and Murine Intracellular Carboxylesterases," Biochemistry (Moscow), Vol. 69, No. 4, 2004, pp. 381386. doi: 10.1023/B:BIRY.0000026192.26188.b9

[4] A. A. Sulaiman, N. N. Al-Shawi, A. H. Jwaied, D. M. Mahmood and S. A. Hussain, "Protective Effect of Melatonin against Chlorpromazine-Induced Liver Disease in Rats," Saudi Medical Journal, Vol. 27, No. 10, 2006, pp. 1477-1482.

[5] A. Pillai, V. Parikh, A. V. Terry Jr. and S. P. Mahadik, "Long-Term Antipsychotic Treatments and Crossover Studies in Rats: Differential Effects of Typical and Atypical Agents on the Expression of Antioxidant Enzymes and Membrane Lipid Peroxidation in Rat Brain," Journal Psychiatry Research, Vo. 41, No. 5, 2007, pp. 372-386.

[6] J. M. van Zyl, K. Basson, A. Kriegler and B. J. van der Walt, "Activation of Chlorpromazine by the Myeloperoxidase System of the Human Neutrophil," Biochemical Pharmacology, Vol. 40, No. 5, 1990, pp. 947-954. doi: 10.1016/0006-2952(90)90478-4

[7] P. P. Kelder, N. J. de Mol, M. J. Fischer and L. H. Janssen, "Kinetic Evaluation of the Oxidation of Phenothiazine Derivatives by Methemoglobin and Horseradish Peroxidase in the Presence of Hydrogen Peroxide. Implications for the Reaction Mechanisms," Biochimica at Biophysica Acta, Vol. 1205, No. 2, 1994, pp. 230-238. doi: 10.1016/0167-4838(94)90238-0

[8] R. A. Løvstad, "Activating Effect of Chlorpromazine on the Peroxidase-Catalysed Oxidation of Catecholamines," General Pharmacology, Vol. 10, No. 6, 1976, pp. 437440.

[9] M. A. Eghbal, S. Tafazoli, P. Pennefather and P. J. O'Brien, "Peroxidase Catalysed Formation of Cytotoxic Prooxidant Phenothiazine Free Radicals at Physiological $\mathrm{pH}$," Chemico-Biological Interactions, Vol. 151, No. 1, 2004, pp. 43-51. doi: 10.1016/i.cbi.2004.10.005

[10] V. F. Ximenes, A. P. Rodrigues, C. Cabello, M. L. de
Menezes and J. R. Fernandes, "The Co-Catalytic Effect of Chlorpromazine on Peroxidase-Mediated Oxidation of Melatonin: Enhanced Production of N1-acetyl-N2-formyl-5-methoxykynuramine," Journal of Pineal Research, Vol. 44, No. 2, 2008, pp. 115-120. doi: 10.1111/j.1600-079X.2007.00497.x

[11] S. Muraoka and T. Miura, "Inactivation of Cholinesterase Induced by Chlorpromazine Cation Radicals," Pharmacology and Toxicology, Vol. 92, No. 2, 2003, pp. 100-104. doi: 10.1034/j.1600-0773.2003.920207.x

[12] J. Gutiérrez-Correa, R. L. Krauth-Siegel and A. O. Stoppani, "Phenothiazine Radicals Inactivate Trypanosoma cruzi Dihydrolipoamide Dehydrogenase: Enzyme Protection by Radical Scavengers," Free Radical Research, Vol. 37, No. 3, 2003, pp. 37, 281-291.

[13] D. J. Goodwin, T. A. Grover and S. D. Aust, "Redox Mediation in the Peroxidase-Catalyzed Oxidation of Aminopyrine: Possible Implications for Drug-Drug Interaction," Chemical Research in Toxicology, Vol. 9, No. 2, 1996, pp. 476-483. doi: 10.1021/tx950186t

[14] H. Salminen and M. J. Heinone, "Plant Phenolics Affect Oxidation of Tryptophan," Journal Agricultural and Food Chemistry, Vol. 56, No. 16, 2008, pp. 7472-7481. doi: $10.1021 / \mathrm{jf} 800708 \mathrm{t}$

[15] V. F. Ximenes, A. S. Pessoa, C. Z. Padovan, D. H. Abrantes, F. H. F. Gomes, M. A. Maticoli and M. L. de Menezes, "Oxidation of Melatonin by AAPH-Derived Peroxyl Radicals: Evidence of a Pro-Oxidant Effect of Melatonin," Biochimica et Biophysica Acta, Vol. 1790, No. 8, 2009, pp. 787-792. doi:10.1016/j.bbagen.2009.03.021

[16] H. Y. Cheng, P. H. Sackett and R. L. Mccreery, "Kinetics of Chlorpromazine Cation Radical Decomposition in Aqueous Buffers," Journal of the American Chemical Society, Vol. 100, No. 3, 1978, pp. 962-967. doi: 10.1021/ja00471a051

[17] M. Gracanin, C. L. Hawkins, D. L. Pattison and M. J. Davies, "Singlet-Oxygen-Mediated Amino Acid and Protein Oxidation: Formation of Tryptophan Peroxides and Decomposition Products," Free Radical Biology and Medicine, Vol. 47, No. 1, 2009, pp. 92-102. doi:10.1016/j.freeradbiomed.2009.04.015

[18] S. Barnes, E. M. Shonsey, S. M. Eliuk, D. Stella, K. Barrett, O. P. Srivastava, H. Kim and M. B. Renfrow, "High-Resolution Mass Spectrometry Analysis of Protein Oxidations and Resultant Loss of Function," Biochemical Society Transactions, Vol. 36, No. 5, 2008, pp. 10371044. doi: 10.1042/BST0361037

[19] P. Kumar, U. Devi, S. Ali, R. Upadhya, S. Pillai, A. Raja, S. Rao and A. Rao, "Plasma Protein Oxidation in Patients with Brain Tumors," Neurological Research, Vol. 31, No. 3, 2009, pp. 270-273. doi:10.1179/174313209X382296

[20] D. Silva, C. M. Cortez and S. R. Louro, "Chlorpromazine Interactions to Sera Albumins. A Study by the Quenching of Fluorescence," Spectrochimica Acta Part A: Molecular and Biomolecular Spectroscopy, Vol. 60, No. 5, 2004, pp. 1215-1223. doi:10.1016/j.saa.2003.08.003

[21] W. Jantschko, P. G. Furtmüller, M. Allegra, M. A. Livrea, C. Jakopitsch, G. Regelsberger and C. Obinger, "Redox 
Intermediates of Plant and Mammalian Peroxidases: A Comparative Transient-Kinetic Study of Their Reactivity Toward Indole Derivatives," Archives Biochemistry and Biophysics, Vol. 398, No. 1, 2002, pp. 12-22. doi:10.1006/abbi.2001.2674

[22] M. Staniszewska and R. H. Nagaraj, "Detection of Kynurenine Modifications in Proteins Using a Monoclonal Antibody," Journal Immunological Methods, Vol.
324, No. 1-2, 2007, pp. 63-73.

doi: $10.1016 /$ j.jim.2007.05.002

[23] M. Ehrenshaft, S. S. de Oliveira, I. Perdivara, P. Bilski, R. H. Sik, C. F. Chignell, K. B. Tomer and R. P. Mason, "Immunological Detection of $\mathrm{N}$-formylkynurenine in Oxidized Proteins," Free Radical Biology and Medicine, Vol. 46, No. 9, 2009, pp. 1260-1266.

doi: 10.1016/j.freeradbiomed.2009.01.020 